\title{
Patients with Alcohol Problems in the Emergency Department, Part 1: Improving Detection*
}

\author{
GAIL D'ONOFRIO, MD, EDWARD BERNSTEIN, MD, \\ JUdith BERNSTEIN, PHD, ROBERT H. WOOLARD, MD, \\ Phillip A. BREWER, MD, SANDRA A. CRAIG, MD, BRIAN J. ZINK, MD, \\ FOR THE SAEM SUBSTANCE ABUSE TASK FORCE
}

Abstract. Medical and social problems related to alcohol use are frequently seen in the ED. Often, the tempo of emergency medicine practice seems to preclude assessment beyond that required by the acute complaint. However, detection of ED patients with alcohol problems can occur using brief screening tools. This article was developed by members of the SAEM Substance Abuse Task Force, and describes screening tools that have been used successfully to identify at- risk and dependent drinkers. Their brevity, reproducibility, and accuracy vary somewhat, but screening can be realistically performed in the busy ED setting. The early detection of patients with alcohol problems would provide the opportunity for early intervention, and may reduce subsequent morbidity and mortality in this patient population. Key words: alcohol abuse; ED screening; intervention. ACADEMIC EMERGENCY MEDICINE 1998; 5:1200-1209

\begin{abstract}
A LCOHOL use is pervasive in our society, and alcohol abuse is a major health threat. No other specialist sees more of the negative consequences of the disease than the emergency physician (EP). Illnesses and injuries associated with alcohol present across the entire spectrum of drinking behavior from "social drinking" to severe dependence. Because the majority of alcohol problems are not detected at the time of the ED visit, a valuable opportunity for brief intervention and prevention of further morbidity and mortality is often lost.

This article reviews the epidemiology and scope of the problem, the screening and assessment tools available to the $\mathrm{EP}$, and a realistic approach to brief intervention and treatment/referral options within the constraints of an ED visit. Finally, evidence is presented to demonstrate that, contrary
\end{abstract}

From the Section of Emergency Medicine, Yale University School of Medicine (GD, PAB), New Haven, CT; the Department of Emergency Medicine, Boston University School of Medicine (EB), Boston, MA; the Department of Maternal and Child Health, Boston University School of Public Health (JB), Boston, MA; the Department of Emergency Medicine, Brown University School of Medicine (RHW), Providence, RI; the Department of Emergency Medicine, Carolinas Medical Center, (SAC), Charlotte, NC; and the Section of Emergency Medicine, University of Michigan Medical School (BJZ), Ann Arbor, MI. Received March 10, 1998; revision received July 15, 1998; accepted July 15, 1998.

Address for correspondence and reprints: Gail D'Onofrio, MD, Section of Emergency Medicine, 464 Congress Avenue, New Haven, CT 06519. Fax: 203-319-0095; e-mail: gail.donofrio@yale. edu

*Part 2 follows in this issue of Academic Emergency Medicine. to commonly held beliefs, EPs can assist patients to change drinking behaviors, and treatment for substance abuse does work.

\section{SCOPE OF THE PROBLEM}

Alcohol affects the individual drinker directly but also has far-reaching implications for families, communities, workplaces, and the health care system. It is estimated that the overall annual economic cost to the nation is $\$ 100$ billion, with nearly $\$ 27$ billion per year reported in lost productivity to American industry. ${ }^{1-3}$ In addition, an estimated 28 million children of alcoholics are at risk because of family dysfunction associated with alcoholism. ${ }^{4}$

Alcohol is the drug most commonly used by Americans. Approximately 111 million people in the United States aged 12 years or more drink alcohol regularly. ${ }^{5}$ A recent survey showed that $25 \%$ of 8 th graders and $50 \%$ of 12 th graders report consuming alcohol within the preceding month. More alarmingly, $15 \%$ of the 8 th graders and $28 \%$ of the 12th graders report binge drinking in the preceding two weeks (five or more drinks on one occasion). ${ }^{6}$ Young adults have a higher prevalence of alcohol consumption than all the other age groups, and recent instances of alcohol overdose among college students have stimulated concern on college campuses across the nation. The National Household Survey on Drug Abuse reported that 33.7\% of persons between the ages of 19 and 28 years engaged in binge drinking or drank heavily (five or more drinks on each of five or more days) in the preceding 30 days. $^{5}$ 
Elder patients constitute another "hidden group" with major health problems related to drinking. At least $10 \%$ of patients in EDs who have alcohol-related medical problems are over the age of 60 years. $^{7}$ In this age group even small amounts of alcohol can cause major problems. Alcohol has been shown to interact with at least half of the 100 most frequently prescribed drugs.

In elder patients, "the onset or continuation of drinking behavior becomes problematic because of physiological and psychosocial changes that occur with aging, including increased sensitivity to alcohol effects." Dependent drinking is a particularly acute problem in elder men because of its prevalence (5:1 ratio of men to women in this age group), and because of its association with depression and suicide attempts. Because women live longer, experience a higher level of disability, and seek medical care more often, alcohol abuse among elder women is also a significant issue and an economic drain on the health care system. ${ }^{7}$ Among the 30 million people in the United States who will be 60 years old or older in the year 2000 , approximately 1 million will be dependent drinkers, and an even larger number will have alcohol-related health problems. ${ }^{7}$

Among Americans aged 18 years and older, 5\% (10 million) are dependent drinkers, $20 \%$ (40 million) are considered high-risk drinkers, $35 \%$ drink moderately and are at low risk for alcohol problems, and the remaining $40 \%$ abstain from alcohol use. ${ }^{8}$ The lifetime prevalence of alcohol abuse and dependence is estimated somewhere between $13.7 \%$ and $23.5 \%$, with the current prevalence estimated to be $4.8 \%$ to $9.7 \%$ from two large population-based surveys. ${ }^{9.10}$ The prevalence rates for these disorders were two to three times higher for men than women for both lifetime and current problems.

\section{MORBIDITY AND MORTALITY}

Alcoholism is the leading cause of morbidity and mortality in the United States." More than 107,000 alcohol-related deaths are reported each year. ${ }^{3} \mathrm{Up}$ to one third of adult inpatients have problems related to alcohol, and $20 \%$ of the total national expenditure for hospital care is related to alcohol abuse. ${ }^{1,12}$

Alcohol has been shown to be an attributable risk factor in multiple disease states, including breast cancer $(13 \%)$, chronic pancreatitis $(72 \%)$, and cirrhosis ( $74 \%$ ). Eighty percent of esophageal cancer is attributable to smoking and alcohol. ${ }^{13}$ There are more than 60 ICD-9 codes identified as alcohol-related conditions.

Alcohol is the major risk factor for virtually all categories of injury, e.g., motor vehicle crashes
(MVCs), pedestrian and cycle injuries, falls, burns, drownings, suicides, crimes involving assault, rape, and murder, and all forms of domestic violence, including spousal battering and sexual assault..$^{3.14-26}$ Nearly 50\% of trauma patients are injured while under the influence of alcohol. ${ }^{27}$ MVCs are the single largest cause of death in the United States for persons between the ages of 5 and 34 years. Nearly half of the approximately 35,000 fatal MVCs are alcohol-related. ${ }^{28}$ Although adults between the ages of 16 and 25 years make up $15 \%$ of U.S. licensed drivers, they constitute $30 \%$ of alcohol-related driving fatalities. ${ }^{29}$ In a single MVC between midnight and $6 \mathrm{AM}$, the chance of a driver's being under the influence of alcohol is $94 \% .30$

\section{TREATMENT WORKS}

Early detection of alcohol problems and referral to treatment confer benefit to the health status of the individual and save health care dollars. Brief intervention has shown to be of benefit in multiple randomized, controlled trials in primary care and community-based settings. ${ }^{31-34}$ In spite of this knowledge, only $11 \%$ of the 14 million people who abuse or are dependent on alcohol receive treatment in any calendar year. ${ }^{8}$

Studies have consistently demonstrated that treatments for addictions are cost-effective. ${ }^{35,36}$ The health care costs of untreated alcoholic individuals are at least $100 \%$ higher than those of nonalcoholic individuals. ${ }^{35}$ Monthly health care costs of untreated alcoholic persons have been shown to be $24 \%$ higher than those of nonalcoholic persons over a 4-month posttreatment period. ${ }^{37}$ The California Drug and Alcohol Treatment Assessment Study showed that $\$ 7$ was saved for every dollar invested in treatment. ${ }^{38}$

\section{THE ED: A CRITICAL SETTING FOR SCREENING, BRIEF INTERVENTION, AND REFERRAL TO TREATMENT}

Opportunities for Screening. The ED offers a unique opportunity for detection, intervention, and referral of patients with problem drinking. As many as $38 \%$ of all patients presenting to the ED are legally intoxicated at the time of the visit. ${ }^{15,26}$ In addition, many patients with high-risk drinking behaviors may present without evidence of acute intoxication. ${ }^{39}$ Bernstein et al. reported that $31 \%$ of patients presenting to an urban ED had two or more positive CAGE responses and $13 \%$ were biochemically positive (saliva alcohol test). ${ }^{40}$

The failure of ED staff to detect and refer patients for counseling and rehabilitation, in spite of the high prevalence of patients with alcohol-re- 
lated conditions and the known association between alcohol and injury, is distressing and well documented. ${ }^{16.41-46}$ Lowenstein et al., for example, reported that of 153 intoxicated patients, only $13 \%$ received referral for counseling and/or rehabilitation. Reasons cited for lack of recognition and referral include inadequate time, insufficient education, and lack of resources. Provider attitudes of disinterest, avoidance, disdain, or pessimism are also common, especially when confronted with a hostile, manipulative, or combative patient. ${ }^{16}$ The importance of identifying problem drinkers was recently noted by Davidson et al., who reported that a single alcohol-related ED visit is an important predictor of continued problem drinking, alcoholimpaired driving, and, possibly, premature death. ${ }^{47}$

Opportunities for Intervention. The ED is an excellent site for brief intervention with problem drinkers. The first principle of successful intervention is that it comes to people, instead of waiting for people to seek it out. The second is that the intervention must be timely. The ED visit meets both criteria; patients are often more receptive to education in the moment of crisis (an illness or injury that requires acute care. $)^{48}$

The care of the patient with alcohol problems can be rewarding. However, the EP must first acquire the knowledge and skills necessary to provide that care. Effective new tools specifically designed for the hectic environment of the typical ED permit care providers to screen, assess, intervene with, and refer patients who have alcohol problems, and reduce the harm associated with abuse.

\section{DEFINITIONS/TERMINOLOGY}

There is no individual finding that is pathognomonic of alcoholism, nor is there agreement on a single set of criteria for the diagnosis. Alcoholism is defined by the American Society of Addiction Medicine (ASAM) and the National Council on Alcoholism and Drug Dependence (NCADD) as:

A primary chronic disease with genetic, psychosocial, and environmental factors influencing its development and manifestations. The disease is often progressive and fatal. It is characterized by impaired control over drinking, preoccupation with the drug alcohol, use of alcohol despite adverse consequences, and distortions in thinking, most notably denial. Each of these symptoms may be periodic or continuous. ${ }^{49}$

The American Psychiatric Association have developed specific diagnostic criteria for alcoholism, defined as substance abuse and substance dependence in the Diagnostic and Statistical Manual of
Mental Disorders (DSM IV). ${ }^{50}$ These criteria are based on consequences of use. The diagnosis of alcohol abuse (high risk or harmful use) is based on a finding of maladaptive patterns of use within a 12-month period with clinically significant impairment. Abuse is evident when substances are used in spite of knowledge of significant negative physical or psychosocial consequences. Use in hazardous situations, i.e., driving under the influence of alcohol, is an example of maladaptive behavior. According to DSM IV, the diagnosis of alcohol or substance abuse is usually made before dependence has developed.50

Abuse is diagnosed when one or more of the following are present:

1. Use results in failure to fulfill major role obligations at work (absences, poor performance), at school (absences, suspensions), or at home (neglect of children or household).

2. Recurrent use in physically harmful situations (driving while intoxicated).

3. Recurrent substance-related legal problems.

4. Continued use despite resulting exacerbation of persistent or recurrent social or interpersonal problems.

Alcohol or substance dependence is characterized by loss of control over use, and development of tolerance or withdrawal symptoms. Problems maintaining life roles, work responsibilities, and family activities are usually encountered. According to DSM IV,,$^{50}$ at least three of the following criteria must be met during a 12-month period to make this diagnosis:

1. Tolerance manifested by the need for markedly increased amounts of substance over time to achieve intoxication or the desired effect or by markedly diminished effect with continued use of the same amount of the substance.

2. Withdrawal manifested by a characteristic withdrawal syndrome or substance (or closely related substitute) taken to relieve or avoid withdrawal symptoms.

3. Consumption of larger amounts of substance over a longer period of time than intended.

4. Persistent desire or unsuccessful attempts to cut down on or control use.

5. A great deal of time spent in substance-related activities, obtaining the substance, consuming the substance, or recovering from the substance's effects.

6. Important social, occupational, or recreational activities given up or reduced because of substance use.

7. Continued substance use despite knowledge of a recurrent psychological or physical problem that is likely to have been caused or exacerbated by use.

A diagnosis of abuse or dependence is entertained when symptoms have persisted for at least 
one month or have recurred over a longer period of time. Dependence is accompanied by a compulsion to drink, an inability to stop once started, a pattern of drinking to avoid withdrawal, consumption of increasing amounts to get "high," and/or signs of withdrawal: tremor, nausea, sweating, and mood disturbance. Symptoms and impairment of function can range in severity from mild with undisturbed functionality to severe with loss of social and occupational functioning.

High-risk or at-risk drinking is another category describing behaviors that may lead to adverse health consequences over time. The National Institute on Alcohol Abuse and Alcoholism (NIAAA) ${ }^{51}$ defines a patient who may be at risk for alcoholrelated problems as:

Male aged 21-65 yr

consuming $>14$ drinks per week or $>4$ drinks per occasion

Female aged 21-65 yr consuming $>7$ drinks per week or $>3$ drinks per occasion

Male or female aged $>65 \mathrm{yr}$

consuming $>7$ drinks per week or $>3$ drinks per occasion

In addition, the term harmful drinking has been used to identify patients who already have negative health consequences as a result of alcohol consumption. Hazardous drinking is used in situations such as driving while intoxicated, in which individuals are at risk for negative health consequences. Presumably patients who present to the ED with illnesses or injuries related to alcohol are now beyond risk and have experienced a harmful, negative consequence. ${ }^{52}$

In light of the fact that patients presenting to the ED with illness/injury represent a spectrum of problems ranging from at-risk to dependence, the authors throughout the text refer to the broadbased category of patients with alcohol problems, or the individual problem drinker, as all-inclusive terms. The NIAAA definition of risk based on quantity and frequency allows interventions early in the process, and is appropriate to the ED setting.

\section{HIGH-RISK INDICATORS}

The high prevalence of alcohol-related problems among patients presenting to the ED suggests that most ED patients should be screened for alcohol abuse. Injury represents an even higher risk. ${ }^{53} \mathrm{ED}$ patients who are intoxicated after major injury are very likely to have chronic alcoholism. Of admitted trauma patients found to be intoxicated in the ED, $75 \%$ of adults and almost $50 \%$ of adolescents have evidence of chronic alcoholism. ${ }^{54-56}$ Certain presentations, such as injury, abdominal pain, gastrointestinal complaints, seizures, change in mental status, hypertension, ingestions, and use of other drugs of abuse, should prompt the EP to screen for alcohol problems. Other historical factors related to alcohol use that may be detected on a review of systems include fatigue, headaches, somatic complaints, sexual problems, weight loss, and symptoms of psychiatric illness, depression, and suicidal ideation. ${ }^{57-60} \mathrm{~A}$ host of other medical conditions, including cardiac dysrhythmias, cellulitis, peripheral neuropathy, and cancers of the oropharynx, larynx, breast, and liver, also may prompt screening. ${ }^{61-63}$

Social problems, divorce, financial losses, job changes, tardiness, absenteeism, and arrests are other risk factors that may lead to further questioning about alcohol use. Lack of eye contact, pauses before answering, uncomfortable posture, or other signs of anxiety during the interview may be a clue to problems with drinking alcohol.

A family history of alcohol problems and a past history of abuse are risk factors for alcohol problems. First-degree relatives of alcoholic individuals have been found to have a four to five times higher risk of developing alcoholism. ${ }^{5}$

On physical examination the EP may note signs of withdrawal, such as tremors, tachycardia, or an enlarged liver or other stigmata of liver disease. A new diagnosis of any alcohol-related condition should prompt an exploration of alcohol use with the patient.

\section{SCREENING}

A variety of screening instruments are available. Their effectiveness varies according to their availability, ease of administration, adverse consequences, and test characteristics. ${ }^{64}$ Because these tools have not all been evaluated in the same manner, comparing their degrees of usefulness in different clinical settings may be problematic. While there is no criterion standard, structured interviews that can classify individuals into DSM categories are probably the best. These include the Diagnostic Interview Schedule (DIS), ${ }^{65}$ the Structured Clinical Interview for DSM-III-R (SCID), ${ }^{66}$ and the Composite International Diagnostic Interview (CIDI), which yields a DSM-IV abuse and dependence diagnosis. ${ }^{50}$ Although these interview schedules have proved valuable for research, they are lengthy and time-consuming and not practical for use in the ED.

When using screening tests, it is important to identify the alcohol problem as current or past. Different instruments may identify current use only, or current and past use. Considering the chronic nature of alcohol problems, information regarding prior use may be helpful in assessing current health problems and determining treatment options. 


\begin{tabular}{|c|c|c|}
\hline & \multicolumn{2}{|c|}{$\begin{array}{l}\text { Weighted } \\
\text { Scoring } \\
\text { System }\end{array}$} \\
\hline & Yes & No \\
\hline 1. Do you feel you are normal drinker? & 0 & 2 \\
\hline $\begin{array}{l}\text { 2. Do friends or relatives think you are a } \\
\text { normal drinker? }\end{array}$ & 0 & 2 \\
\hline $\begin{array}{l}\text { 3. Have you ever attended a meeting of } \\
\text { Alcoholics Anonymous? }\end{array}$ & 5 & $\mathbf{0}$ \\
\hline $\begin{array}{l}\text { 4. Have you ever lost friends or girl- } \\
\text { friends/boyfriends because of drinking? }\end{array}$ & 2 & $\mathbf{0}$ \\
\hline $\begin{array}{l}\text { 5. Have you ever gotten into trouble at } \\
\text { work because of drinking? }\end{array}$ & 2 & $\mathbf{0}$ \\
\hline $\begin{array}{l}\text { 6. Have you ever neglected your obliga- } \\
\text { tions, your family, or your work for two } \\
\text { or more days in a row because you were } \\
\text { drinking? }\end{array}$ & 2 & 0 \\
\hline $\begin{array}{l}\text { 7. Have you ever had delirium tremens } \\
\text { (DTs), severe shaking, heard voices, } \\
\text { seen things that weren't there after } \\
\text { heavy drinking? }\end{array}$ & 2 & 0 \\
\hline $\begin{array}{l}\text { 8. Have you ever gone to anyone for help } \\
\text { about your drinking? }\end{array}$ & 5 & 0 \\
\hline $\begin{array}{l}\text { 9. Have you ever been in a hospital be- } \\
\text { cause of drinking? }\end{array}$ & 5 & 0 \\
\hline $\begin{array}{l}\text { 10. Have you ever been arrested for drunk } \\
\text { driving or driving after drinking? }\end{array}$ & 2 & 0 \\
\hline
\end{tabular}

*MAST = Michigan Alcoholism Screening Test.

Several screening techniques are available to the EP, including structured questionnaires such as the CAGE, TWEAK, AUDIT, and Brief MAST as well as drug and alcohol laboratory tests.

Questionnaires. Several structured screening tests can be used to determine current and/or past alcohol use, and increase the sensitivity of self-report and clinical observation.

The Michigan Alcohol Screening Test (MAST) ${ }^{67}$ includes 25 questions related to the consequences of alcohol use, and includes current and past problems, Its validity, reliability, and internal consistency are well established. A shorter version has been developed with ten questions, known as the Brief MAST (or BMAST) ${ }^{68}$ (Table 1). The answers are weighted with a cutoff score of 6 used as a positive indicator for alcohol abuse and dependence.

The Alcohol Use Disorders Identification Test (AUDIT), a ten-item questionnaire, was developed as a screening instrument for hazardous and harmful alcohol consumption as part of a 12-country World Health Organization study of brief alcohol interventions ${ }^{69,70}$ (Table 2). Alcohol consumption, drinking behavior, and alcohol-related problems are assessed over the preceding year. A cutoff score of 8 out of a possible 41 is used as a positive indicator of hazardous/harmful drinking.

Instruments such as the $\mathrm{CAGE}^{71,72}$ and TWEAK $^{73}$ are brief and easier to administer. Although they are designed for assessing lifetime use and abuse, they can be prefaced with the phrase "in the preceding 12 months" to detect current problems.

CAGE is a mnemonic for the following questions:

1. Have you ever felt that you should cut down on your drinking?

2. Have people annoyed you by criticizing your drinking?

3. Have you ever felt bad or guilty about you've drinking?

4. Have you ever had a drink first thing in the morning to steady your nerves or get rid of a hangover (eye-opener)?

The sensitivity, specificity, and positive predictive values for different CAGE scores at varying prevalences of alcohol abuse and dependence can be seen in Table $3 .^{.64}$

The TWEAK was originally designed to identify "at-risk" pregnant drinkers. It has been found to have high sensitivity and specificity in both primary care and general populations, ranging from $83 \%$ to $100 \%$ and $68 \%$ to $96 \%$, respectively, using a cutoff point of 3 , when a weight of 2 is applied to tolerance and worry and a weight of 1 is applied to the other three. ${ }^{39,74}$ TWEAK is a mnemonic for the following questions:

1. Can you hold six or more drinks (tolerance)?

2. Are your friends or relatives worried about your drinking?

3. Have you ever had an eye-opener (taken a drink early in the morning to get going)?

4. Have you had blackouts (amnesia)?

5. Have you ever felt the need to "kut" down on your drinking?

Cherpitel studied the use of questionnaires, including the AUDIT, Brief MAST, CAGE, and TWEAK, as well as self-report and breath alcohol analysis in screening and assessing ED patients with alcohol problems ${ }^{39}$ (Table 4). She found that TWEAK was the best of the screening instruments for the detection of harmful and dependent drinking. At a cutoff point of 3 positive answers, the sensitivity for TWEAK was $87 \%$ (harmful) $/ 84 \%$ (dependent), and the specificity was $86 \% / 86 \%$. The AUDIT was almost comparable. The AUDIT, with a cutoff score of 8 , had a sensitivity of $85 \% / 83 \%$ and a specificity of $88 \% / 90 \%$. With a cutoff point of 2 positive answers, the sensitivity of CAGE was $75 \% / 76 \%$ and the specificity was $88 \% / 90 \%$. The 
Brief MAST had a low sensitivity of $31 \% / 30 \%$ and a high specificity of $98 \% / 99 \%$ at a cutoff score of 4 . In the same study, breath alcohol analysis had a low sensitivity $(20 \% / 20 \%)$ and a high specificity $94 \% / 94 \%$, similarly to self-report without a structured questionnaire, with a sensitivity of $31 \% / 29 \%$ and a specificity of $89 \% / 89 \% .39 .75$

Differences noted in this study for race, gender, and presence of injury on all of the screening tests warrant further investigation. However, one should not discredit the usefulness of these instruments. None were as sensitive for females as for males, although the TWEAK may be more genderneutral than CAGE, since it was originally developed as an assessment tool for pregnant women. The sensitivities of breath alcohol analysis, CAGE, AUDIT, and self-report were found to be higher among black subjects. ${ }^{39,76}$ The CAGE appeared to be more sensitive for those presenting with injury, $84 \%$.

Based on this work and other studies reporting underidentification of problem drinking, ${ }^{42}$ alcohol testing and self-report without structured questions cannot be recommended to stand alone as screening tests. In a primary care office setting, other investigators have found that having had a drink within the preceding 24 hours and answering positively to the question "Have you ever had a drinking problem?" provide a more than $90 \%$ sensitivity and an $85 \%$ specificity as a screening tool for identifying the alcoholic individual when combined with two or more positive answers on the CAGE. ${ }^{77}$

Data suggest that patients' responses to structured questions can be influenced by the skill level of the interviewing physician. Patients tend to re-

TABLE 2. The AUDIT*

1. How often do you have a drink containing alcohol?

0 Never

1 Monthly or less

22 to 4 times a month

32 to 3 times a week

44 or more times a week

2. How many drinks containing alcohol do you have on a typical day when you are drinking?

0 None

11 or 2

23 or 4

35 or 6

47 or 9

510 or more

3. For males: How often do you have four or more drinks at one occasion? For females: How often do you have three or more drinks at one occasion?

0 Never

1 Less than monthly

2 Monthly

3 Weekly

4 Daily or almost daily

4. How often during the last year have you found that you were unable to stop drinking once you had started?

0 Never

1 Less than monthly

2 Monthly

3 Weekly

4 Daily or almost daily

5. How often during the last year have you failed to do what was normally expected of you because of drinking?

0 Never

1 Less than monthly

2 Monthly

3 Weekly

4 Daily or almost daily
6. How often during the last year have you needed a first drink in the morning to get yourself going after a heavy drinking session?

0 Never

1 Less than monthly

2 Monthly

3 Weekly

4 Daily or almost daily

7. How often during the last year have you had a feeling of guilt or remorse after drinking?

0 Never

1 Less than monthly

2 Monthly

3 Weekly

4 Daily or almost daily

8. How often during the last year have you been unable to remember what happened to you the night before because of drinking?

0 Never

1 Less than monthly

2 Monthly

3 Weekly

4 Daily or almost daily

9. How often during the last year have you or someone else been injured as a result of your drinking?

0 Never

1 Less than monthly

2 Monthly

3 Weekly

4 Daily or almost daily

10. How often during the last year has a relative, a friend, or a doctor or other health worker been concerned about your drinking or suggested you cut down?

0 Never

1 Less than monthly

2 Monthly

3 Weekly

4 Daily or almost daily

${ }^{*}$ AUDIT $=$ Alcohol Use Disorders Identification Test. 
TABLE 3. Sensitivity, Specificity, and Positive Predictive Values for Different CAGE Scores at Varying Prevalences of Alcohol Abuse and Dependence*

\begin{tabular}{|c|c|c|c|c|c|}
\hline \multirow[b]{2}{*}{$\begin{array}{l}\text { CAGE } \\
\text { Score }\end{array}$} & \multirow[b]{2}{*}{$\begin{array}{l}\text { Sensi- } \\
\text { tivity }\end{array}$} & \multirow[b]{2}{*}{$\begin{array}{l}\text { Speci- } \\
\text { ficity }\end{array}$} & \multicolumn{3}{|c|}{ Positive Predictive Value } \\
\hline & & & $\begin{array}{c}10 \% \\
\text { Prevalence }\end{array}$ & $\begin{array}{c}20 \% \\
\text { Prevalence }\end{array}$ & $\begin{array}{c}30 \% \\
\text { Prevalence }\end{array}$ \\
\hline$\geq 1$ & $86-90$ & $52-93$ & $15-20$ & $25-35$ & $40-50$ \\
\hline$\geq 2$ & $74-78$ & $76-96$ & $30-60$ & $55-75$ & $65-80$ \\
\hline$\geq 3$ & $44-54$ & $92-99$ & $60-75$ & $75-80$ & $80-95$ \\
\hline$\geq 4$ & $24-26$ & 100 & $90-99$ & $95-99$ & $\geq 99$ \\
\hline
\end{tabular}

*Reproduced with permission from: Schorling JB, Buchsbaum DG. Screening for alcohol and drug problems. In: Samet J. Alcohol and Other Substance Abuse. Med Clin North Am. 1997; 81:850.

TABLE 4. Sensitivity (S) and Specificity (SP) for Screening Instruments for Harmful and Dependent Drinkers*

\begin{tabular}{llllll}
\hline & \multicolumn{2}{c}{ Harmful } & & \multicolumn{2}{c}{ Dependent } \\
\cline { 2 - 3 } \cline { 5 - 6 } Screening Instrument & S & SP & & S & SP \\
\hline CAGE & 75 & 88 & 76 & 90 \\
TWEAK & 87 & 86 & 84 & 86 \\
AUDIT & 85 & 88 & 83 & 90 \\
Brief MAST & 31 & 98 & 30 & 99 \\
Breath alcohol analysis & 20 & 94 & 20 & 94 \\
Self-report & 31 & 89 & 29 & 89 \\
\hline
\end{tabular}

${ }^{*}$ Reproduced with permission from: Cherpitel CJ. Screening in alcohol problems in the emergency department. Ann Emerg Med. 1995; 26:163-4.

veal less when the CAGE is preceded by direct, closed-ended questions about quantity and frequency of drinking. In these circumstances, the ability of the instrument to detect alcoholism was reduced by a third compared with the standard protocol (CAGE preceded by an open-ended question such as, "Do you drink beer, wine, or liquor now and then?"). ${ }^{78}$

Currently there is no ideal screening questionnaire in the ED. The major concern is to have one sensitive enough to identify as many patients as possible who might benefit from brief intervention and referral for intensive treatment if necessary. In addition, the test should be gender-neutral, sensitive for all racial groups, and applicable for the injured as well as the noninjured patient.

Overall, the CAGE is easiest to administer, and performs relatively well when done face-to-face and not preceded by a quantity-frequency question. For this reason, it is recommended by the NIAAA in The Physician's Guide to Helping Patients with Alcohol Problems ${ }^{51}$ as the initial screening questionnaire. Considering all of the above, we recommend its use in the ED. Because screening tests make patients somewhat defensive, it may be preferable to integrate the CAGE and quantity- frequency questions into the past medical history, separating them in time from a brief intervention.

Laboratory Tests. Blood, saliva, or breath alcohol levels are routinely obtained in many EDs under a variety of screening protocols based on behavioral and medical risk factors such as an unexplained altered mental status. There is mixed evidence about the correlation of alcohol levels with problem drinking. In one study only a third of intoxicated drivers had alcohol problems. ${ }^{79}$ In another, however, there was good correlation between a positive saliva alcohol test $(100 \mathrm{mg} / \mathrm{dL})$ in the ED and harmful drinking, defined as an AUDIT score of 8 or above, and in injured patients a positive saliva alcohol test had a sensitivity of $65.2 \%$ and a specificity of $83.6 \%{ }^{80}$

The original National Council on Alcoholism criteria for alcoholism considered a blood alcohol concentration (BAC) greater than $150 \mathrm{mg} / \mathrm{dL}$ without obvious intoxication as indicative of an alcohol problem, because it indicates significant tolerance. A level of more than $100 \mathrm{mg} / \mathrm{dL}$ in a routine office visit and any level of more than $300 \mathrm{mg} / \mathrm{dL}$ were considered minor criteria for the diagnosis of alcoholism. ${ }^{81}$

Most addiction experts in emergency medicine recommend a primary screening approach of specific questions concerning alcohol. As secondary screening, laboratory testing may be useful to gauge the level of tolerance of some patients who admit to substance use. Laboratory testing also may be helpful when patients are not forthright about substance use and clinical suspicion is high. For example, routine screening for alcohol in trauma, i.e., MVCs and gun assaults, is recommended. Clinical observation is actually less reliable than self-report. Trained observers have been shown to misidentify up to $50 \%$ of intoxicated alcoholic persons as sober. ${ }^{82}$

In addition to the BAC, there are two alternative methods of measuring alcohol content, use of the breath analyzer and saliva content analysis. Both methods allow a rapid determination of alcohol intake and present less risk to the staff than blood sampling. The use of a breath analyzer for ethanol has been demonstrated to correlate highly with blood levels in cooperative patients. ${ }^{83}$ The results obtained with the breath analyzer are approximately within $10 \%$ of the BAC. Falsely elevated results occur if blood or emesis is present in the oral cavity. ${ }^{84}$ Its use is limited by the patient's ability to cooperate or by technical problems such as the recalibration required prior to each use.

Ethanol content also can be measured in the saliva. The saliva alcohol test (SAT) has the advantage of offering immediate results, being nonintrusive, being easy to administer, and not re- 
quiring the cooperation of the patient. ${ }^{85}$ Clinical laboratory studies have reported a close correlation between blood and saliva alcohol levels. ${ }^{86,87}$ Evaluation of the Q.E.D. (Bethlehem, PA) SAT reported an excellent correlation between the saliva and blood samples of 42 healthy volunteers $(r=$ 0.98 ). In no instance did the difference between the two methods exceed $15 \mathrm{mg} / \mathrm{dL} .^{88}$

Liver function tests are not routinely used in the ED to screen for chronic alcohol abuse. However, these tests may reflect alcohol abuse. Mild elevations of AST and ALT with an AST/ALT of $>2 \mathrm{IU} / \mathrm{L}$ and an AST $<350 \mathrm{IU} / \mathrm{L}$ are indicative of alcohol-related liver disease. Similarly, mild macrocytic anemia or thrombocytopenia is suggestive of chronic alcoholism. Whenever clinical and laboratory findings suggest an alcohol-related etiology, the EP should initiate further screening and assessment.

Assessment of Alcohol Consumption. Most screening tests and the standard diagnostic criteria for alcohol abuse and dependence do not include the amount of alcohol consumed. However, alcohol consumption patterns are important because they can help assess the at-risk drinker for potential negative consequences as described earlier by the NIAAA. Asking about the amount an individual drinks may be useful during the medical history in spite of the limitations of self-reported drinking. ${ }^{34}$

Questions regarding quantity and frequency may be triggered after any of the following: 1) positive answers on a screening questionnaire (one CAGE answer positive, or two TWEAK answers positive) 2) positive drug or alcohol laboratory test results, or 3) self-report of drinking or report of a problem with substance use.

Quantity and frequency information can be helpful to match the patient to useful intervention and referral. ${ }^{88}$ The NIAAA recommends the following questions ${ }^{51}$ :

1. On an average, how many days per wenk do you drink alcohol?

2. On a typical day when you drink, how many drinks do you have?

3. What is the maximum number of drinks you had on any given occasion during the last month?

Clinical and laboratory data such as a very high alcohol level with obvious tolerance, presence of signs of withdrawal, and repeated ED visits also identify patient need for treatment. Quantity and frequency questions must be asked with considerable tact, after the initial screening and before counseling begins. Concentrating on "how much do you drink?" early in the screening process or later in the counseling process may only increase patient resistance.

\section{CONCLUSION}

The ED offers a unique opportunity for detection, intervention, and referral of patients with alcoholrelated problems. Patients presenting to the ED have high rates of injury and chronic disease risk, and often lack other sources of routine health care. The ED visit offers a timely opportunity to identify individuals early in the addiction process and intervene effectively. Using a simple screening questionnaire, such as the CAGE, assessment of quantity and frequency of use coupled with self-report of negative consequences, the EP can detect most at-risk and problem drinkers.

\section{References}

1. Burke TR. The economic impact of alcohol abuse and alcoholism. Public Health Rep. 1988; 103:564-8.

2. Duke SB, Gross AC. America's Longest War; Rethinking Our Tragic Crusade against Drugs. New York: G. P. Putnam, 1993.

3. Substance Abuse and Mental Health Services Administration, Office of Applied Studies. 1993 National Household Survey on Drug Abuse. Advance report no. 7. Rockville, MD: Department of Health and Human Services, 1994.

4. Russell M, Henderson C, Blume SB. Children of Alcoholics: A Review of the Literature. New York: Children of Alcoholics Foundation, 1985.

5. Department of Health and Human Services. Eighth Special Report to Congress on Alcohol and Health. National Institute on Alcohol Abuse and Alcoholism. Rockville, Md: Department of Health and Human Services, 1993.

6. Johnston LD, O'Malley PM, Bachman JG. Prevalence of Drug Use among Eighth, Tenth, and Twelfth Grade Students. National Survey Results on Drug Use from the Monitoring the Future Study, 1975-1994: (1) Secondary School Students. NIH Publ. No. 95-4026. Rockville, MD: National Institute of Drug Abuse, 1995, pp 39-76.

7. American Medical Association. Alcoholism in the Elderly: Diagnosis, Treatment, and Prevention; Guidelines for Primary Physicians. Chicago, IL: American Medical Association, 1997. 8. Fuller RK, Perl HI. Screening and treating alcohol problems in primary care medical settings. Frontlines 1996; Nov:1-2.

9. Regier DA, Farmer ME, Rae DS, et al. C(iilorbidity of mental disorders with alcohol and other drug ab ise. JAMA. 1990; 264:2511-8.

10. Kessler RC, McGonagle KA, Zhoa $S$, et al. Lifetime and 12-month prevalence of DSM-III-R psychiatric disorders in the United States. Arch Gen Psychiatry. 1994; 51:8-19.

11. McGinnis JM, Foege WH. Actual causes of death in the United States. JAMA. 1993; 270:2207-12.

12. Rice DP, Kellman S, Miller LS, Dunmeyer S. Estimates of economic costs of alcohol and drug abuse and mental illness, 1985 and 1988. Public Health Rep. 1991; 106:280-92.

13. Lewis DC. The role of the generalist in the care of the substance-abusing patient. In: Samet JH, O'Connor PG, Stein MD (eds). Alcohol and Other Substance Abuse. Med Clin N Am. 1997; 81:845-65.

14. Freedland ES, McMicken DB, D'Onofrio G. Alcohol and trauma. Emerg Med Clin North Am. 1993; 3:225-339.

15. Peppiatt R, Evans R, Jordan P. Blood alcohol concentration of patients attending an accident and emergency department. Resuscitation. $1978 ; 6: 37-43$.

16. Lowenstein SR, Weissberg M, Terry D. Alcohol intoxication, injuries, and dangerous behaviors - and the revolving emergency department door. J Trauma. 19', ); 30:1252-7.

17. Teplin LA, Abram KM, Michaels SK, Sood alcohol levels among emergency room patients: a multivariate analysis. J Stud Alcohol. 1989; 50:441 - 7.

18. Wechsler H, Kasey E, Thumb D, Demone H. Alcohol level 
and home accidents: a study of emergency service patients. Public Health Rep. 1969; 84:1043-50.

19. Shepherd J, Leslie I. Alcohol intoxication and severity of injury in victims of assault. $\mathrm{Br}$ Med J. 1988; 296:1299.

20. Cherpitel CJ. Alcohol and violence-related injuries: an emergency room study. Addiction. 1993; 88:79-88.

21. Cherpitel CJ. Alcohol and injuries: a review of international emergency room studies. Addiction. 1993; 88:651-65.

22. Antti-Poika I, Karaharju E. Heavy drinking and accidents - a prospective study among men of working age. Injury. 1988; 19:198-200.

23. Howland $J$, Hingson $R$. Alcohol as a risk factor for injuries of death due to fires and burns; review of the literature. Public Health Rep. 1987; 102:475-83.

24. Hingson $R$, Howland $J$. Alcohol as a risk factor for injury or death resulting from accidental falls: a review of the literature. J Stud Alcohol. 1987; 48:212-9.

25. Hingson R, Lederman R, Walsh DC. Employee drinking patterns and accidental injury: a study of four New England States. J Stud Alcohol. 185; 46:298-303.

26. Brewer RD, Morris PD, Cole TB, et al. The risk of dying in alcohol related automobile crashes among habitual drunk drivers. N Engl J Med. 1994; 331:513-7.

27. Dunn CW, Donovan DM, Gentilello L. Practical guidelines for performing alcohol interventions in trauma centers. $J$ Trauma. 1997; 42:299-304.

28. Department of Transportation, National Highway Traffic Safety Administration. Alcohol involvement in fatal traffic crashes-1991. Springfield, VA: National Technical Information Service, 1993

29. Campbell KE, Zobeck TS, Bertolucci D. Surveillance Report \#34: Trends in Alcohol-Related Fatal Traffic Crashes, United States, 1977-1993. Rockville, MD: Department of Health and Human Services, 1995.

30. Terhune D, Fell J. The role of alcohol, marijuana, and other drugs in the accidents of injured drivers. In: Proceedings of the 25th Annual Meeting of the American Association for Automotive Medicine, San Francisco, CA, October 1981.

31. Bien T, Miller WR. Brief interventions for alcohol problems: a review. Addiction. 1993; 88:315-36.

32. Chafetz ME, Blane HT, Abram HS, et al. Establishing treatment relations with alcoholics. J Nerv Ment Dis. 1962; 134:395-409.

33. World Health Organization Brief Intervention Study Group. A cross national trial of brief interventions with heavy drinkers. Am J Public Health. 1996; 86:948-55.

34. Fleming MF, Barry KL, Manwill LB, et al. Brief physician advice for problem drinkers: a randomized controlled trial in community based primary care practices. JAMA. 1997; 277: $1039-45$.

35. Holder HD. Alcoholism treatment and potential health care cost savings. Med Care. 1987; 25:52-71.

36. Langenbucher JW, McCrady BS, Brick J, et al. Socioeconomic Evaluations of Addictions Treatment. Washington, DC: Office of National Drug Control Policy, 1993.

37. Holder HD, Bose JD. The reduction of health care costs associated with alcoholism treatment: a 14 year longitudinal study. J Stud Alcohol. 1992; 53:293-302.

38. Evaluating Recovery Services: The California Drug and Alcohol Treatment Assessment. Sacramento, CA: State of California Health and Welfare Agency, Department of Alcohol and Drug Programs, 1994.

39. Cherpitel CJ. Screening for alcohol problems in the emergency department. Ann Emerg Med. 1995; 26:158-66.

40. Bernstein E, Tracey A, Bernstein J, Williams C. Emergency department detection and referral rates for patients with problem drinking. Subst Abuse. 1996; 17:69-76.

41. Soderstrom C, Cowley R. A national alcohol and trauma center survey: missed opportunities, failures of responsibilities. Arch Surg. 1988; 122:1067-71.

42. Chang G, Astrachan $B$. The emergency department surveillance of alcohol intoxication after motor vehicle accidents. JAMA. 1998; 260:2533-6.

43. Becker BM, Woolard RH, Longabaugh R, Minugh PA, Nirenberg TD, Clifford PR. Alcohol use among subcritically injured emergency department patients and injury as a motivator to reduce drinking. Acad Emerg Med. 1995; 2:784-90.
44. Moore RD, Bone LR, Geller G, et al. Prevalence, detection, and treatment of alcoholism in hospitalized patients. JAMA. $1989 ; 261: 403-7$

45. Reyna TM, Hollis HW, Hulsebus RC. Alcohol-related trauma; the surgeon's responsibility. Ann Surg. 1985; 201: 194-7.

46. Kamerow EB, Pincus HA, MacDonald DI. Alcohol abuse, other drug abuse, and mental disorders in medical practice: prevalence, costs, recognition and treatment. JAMA. 986; 255: $2054-7$.

47. Davidson P, Koziol-McLain J, Harrison L, et al. Intoxicated ED patients: a 5-year follow-up of morbidity and mortality. Ann Emerg Med. 1997; 30:593-7.

48. Booth RE, Grosswiler RA. Correlates and predictors of recidivism among drinking drivers. Int J Addiction. 1978; 13: $79-88$.

49. Morse RM, Flavin DK. The definition of alcoholism. JAMA. 1992; 268:1012-4.

50. American Psychiatric Association. Diagnostic and Statistical Manual of Mental Disorders, 4th ed. (DSM-IV). Washington, DC: American Psychiatric Press, 1994.

51. National Institute on Alcohol Abuse and Alcoholism. The Physician's Guide to Helping Patients with Alcohol Problems. U.S. DHHS NIH Publ. No. 95-3769. Washington, DC: PHS, 1995.

52. Bohn MJ, Babor TF, Kranzler HR. The Alcohol Use Disorder Identification Test (AUDIT): validation of a screening instrument for use in medical settings. J Stud Alcohol. 1995; 56: 423-32.

53. Holt S, Stewart I, Dixon J, et al. Alcohol and the emergency service patient. $\mathrm{Br}$ Med $J$. 1980; 281:638-40.

54. Rivara FP, Gurney JG, Ries RK, et al. The magnitude of acute and chronic alcohol abuse in trauma patients. Arch Gen Surg. 1993; 128:907-12.

55. Rivara FP, Gurney JG, Ries RK, et al. A descriptive study of trauma, alcohol and alcoholism in young adults. J Adolesc Health. 1992; 13:663-7.

56. Loiselle JM, Baker MD, Templeton JM, Schwartz G, Drott $H$. Substance abuse in adolescent trauma. Ann Emerg Med. 1993; 22:1530-4.

57. Elangovan N, Berman S, Meinzer D, et al. Substance abuse in psychiatric patients admitted to the emergency room. Proc West Pharmacol Soc. 1991; 34:29-30.

58. Soderstrom CA, Dischinger PC, Smith GS, et al. Psychoactive substance dependence among trauma center patients. JAMA. 1992; 267:2756-9.

59. Hawley CJ, James DV, Birkett BL, et al. Suicidal ideation as a presenting complaint: associated diagnoses and characteristics in a casualty population. Br J Psychiatry. 1991; 159: $232-8$.

60. Sogaard U, Naylor AS, Knopp J, et al. Alcohol abusers in the psychiatric emergency departments in Copenhagen and Frederiksberg. Br J Psychiatry. 1991; 153:567-70.

61. Koskinen P, Kupari M. Alcohol consumption of patients with supraventricular tachyarrhythmias other than atrial fibrillation. Alcohol. 1991; 26:199-206.

62. Kessler R, Ryser DH. The drug abuse patient as emergency. Schweiz Rundsch Med Prax. 1991; 80:31-5.

63. Raymond RC, Warren M, Morris RW, Leikin JB. Periodicity of presentations of drugs of abuse and overdose in an emergency department. J Toxicol Clin Toxicol. 1992; 30:467-78.

64. Schorling JB, Buchsbaum DG. Screening for alcohol and drug abuse. In: Samet JH, O'Connor PG, Stein MD (eds). Alcohol and Other Substance Abuse. Med Clin North Am. 1997; 81:845-65.

65. Robins LN, Helzer JE, Croughan J, et al. National Institute of Mental Health Diagnostic Interview Schedule. Arch Gen Psychiatry. 1981; 38:381-9.

66. Spitzer RL, Williams JBW, Gibbon M, et al. (eds). User's Guide for the Structured Clinical Interview for DSM-III-R. Washington, DC: American Psychiatric Press, 1990.

67. Selzer ML. The Michigan Alcoholism Screening Test: the quest for a new diagnostic instrument. Am J Psychiatry. 1971; 12:89-94.

68. Pokorny AO, Miller BA, Kaplan HB. The Brief MAST: a shortened version of the Michigan Alcohol Screening Test. Am J Psychiatry. 1972; 129:342-5. 
69. Saunders JB, Aasland OG, Babor TF. Development of the Alcohol Use Disorders Identification Test (AUDIT): WHO collaborative project on early detection of persons with harmful alcohol consumption-II. Addiction. 1993; 88:791-803.

70. Bohn MJ, Babor TF, Kranzler HR. The Alcohol Use Disorders Identification Test (AUDIT): validation of a screening instrument for use in medical settings. J Stud Alcohol. 1995; 56:423-31.

71. Ewing JA. Detecting alcoholism: the CAGE questionnaire. JAMA. 1984; 252:1905-7.

72. Mayfield D, McLeod G, Hall P. The CAGE questionnaire: validation of a new alcoholism screening instrument. Am $J$ Psychiatry. 1974; 131:1121-3.

73. Russell M, Marier SS, Sokol FJ, et al. Screening for pregnancy risk-drinking. Alcohol Clin Exp Res. 1994; 18:115661.

74. Chan AWK, Pristach EA, Welte JW, et al. Use of the TWEAK test in screening for alcoholism/heavy drinking in three populations. Alcohol Clin Exp Res. 1993; 17:1188-92.

75. Cherpitel CJ. Analysis of cut-points for screening instruments for alcohol problems in the emergency room. J Stud Alcohol. 1995; 56:695-700.

76. Cherpitel CJ, Clark WB. Ethnic differences in performance of screening instruments for identifying harmful drinking and alcohol dependence in the emergency room. Alcohol Clin Exp Res. 1995; 19:628-34.

77. Cyr MG, Wartman SA. The effectiveness of routine screening questions in the detection of alcoholism. JAMA. 1988; 259: 41-4.

78. Steinweg DL, Worth $\mathrm{H}$. Alcoholism: the keys to the CAGE. Am J Med. 1993; 94:520-3.
79. Gijbers AJ, Raymond A, Whelan G, et al. Does a blood alcohol level of 0.15 or more identify accurately problem drinkers in a drunk-driver population? Med J Austr. 1991; 154: 448-52.

80. Clifford PR, Sparadeo F, Minugh PA, et al. Identification of hazardous/harmful drinking among subcritically injured patients. Acad Emerg Med. 1996; 3:239-45.

81. National Council on Alcoholism. Criteria for the diagnosis of alcoholism. Am J Psychiatry. 1972; 129:127-35.

82. Sobell MB, Sobell LC, VanderSpeck R. Relationships among clinical judgement, self-report and breath analysis measures of intoxication in alcoholics. J Consult Clin Psychol. 1979; 47:204-6.

83. Gibb KA, Yee AS, Martin SD, et al. Accuracy and usefulness of the breath alcohol analyzer. Ann Emerg Med. 1984; 13: 516-20.

84. Gibb KA. Serum alcohol levels, toxicology screens, and use of the breath alcohol analyzer. Ann Emerg Med. 1986; 15: 349-53.

85. Bates ME, Brick $J$, White HR. The correspondence between saliva and breath estimates of blood alcohol concentration: advantages and limitations of the saliva method. J Stud Alcohol. 1993; 54:17-22.

86. Jones AW. Distribution of ethanol between saliva and blood in man. Clin Exp Pharmacol Physiol. 1979; 6:53-9. 87. Jones AW. Inter and intra individual variation on the saliva/blood alcohol rates during ethanol metabolism in man. Clin Chem. 1979; 25:1394-8.

88. Minugh PA, Nirenberg TD, Clifford PR, et al. Analysis of alcohol use clusters among subcritically injured emergency department patients. Acad Emerg Med. 1997; 4:1059-67.

\title{
Announcement/Call for Abstracts SAEM Western Regional Research Forum
}

\author{
March 6-7, 1999 \\ Redondo Beach, California
}

The program committee is accepting abstracts for oral and poster presentation for the SAEM Western Regional Research Forum to be held March 6-7, 1999 in Redondo Beach, California. The deadline for abstract submission is January 13, 1999. Please use the SAEM abstract submission brochure and guidelines for submissions. Becalise this is a regional conference, presentation at the Forum does not preclude presentation at the SAEM Annual meeting. Abstracts may be submitted by fax to Deirdre Anglin, MD, MPH at 323-226-6454, or mailed to the address below.

The registration fee is: faculty $\$ 100$, residents $\$ 50$, and students $\$ 25$. Hotel reservations can be made by calling the Crowne Plaza Redondo Beach and Marina Hotel at 800-368-9760. Be sure to mention the conference to receive the group rate of $\$ 111$. A block of rooms is being held at this rate until February 12, 1999.

For further information contact: Deirdre Anglin, MD, MPH, Department of Emergency Medicine, Los Angeles County/University of Southern California Medical Center, Room 1011, 1200 North State Street, Los Angeles, CA 90033, phone 323-226-6675, fax 323-226-6454, e-mail anglin@ @sc.usc.edu. 